\title{
Sympathetic nerve activity is decreased during device-guided slow breathing
}

\author{
Bruna Oneda, Kátia C Ortega, Josiane L Gusmão, Tatiana G Araújo and Décio Mion Jr
}

It is known that slow breathing ( $<10$ breaths $\mathrm{min}^{-1}$ ) reduces blood pressure (BP), but the mechanisms involved in this phenomenon are not completely clear. The aim of this study was to evaluate the acute responses of the muscle sympathetic nerve activity, BP and heart rate (HR), using device-guided slow breathing (breathe with interactive music (BIM)) or calm music. In all, 27 treated mild hypertensives were enrolled. Muscle sympathetic nerve activity, BP and HR were measured for 5 min before the use of the device $(n=14)$ or while subjects listened to calm music $(n=13)$, it was measured again for 15 min while in use and finally, 5 min after the interventions. BIM device reduced respiratory rate from $16 \pm 3$ beats per minute (b.p.m) to $5.5 \pm 1.8$ b.p.m $(P<0.05)$, calm music did not affect this variable. Both interventions reduced systolic ( -6 and $-4 \mathrm{~mm} \mathrm{Hg}$ for both) and diastolic BPs ( $-4 \mathrm{~mm} \mathrm{Hg}$ and $-3 \mathrm{~mm} \mathrm{Hg}$, respectively) and did not affect the HR ( -1 and -2 b.p.m respectively). Only the BIM device reduced the sympathetic nerve activity of the sample ( -8 bursts $\mathrm{min}^{-1}$ ). In conclusion, both device-guided slow breathing and listening to calm music have decreased BP but only the device-guided slow breathing was able to reduce the peripheral sympathetic nerve activity. Hypertension Research (2010) 33, 708-712; doi:10.1038/hr.2010.74; published online 3 June 2010

Keywords: breathing exercise; high blood pressure; non-pharmacological therapy; sympathetic nervous system

\section{INTRODUCTION}

Slow- and regular-breathing exercises seem to be effective in decreasing blood pressure (BP). ${ }^{1}$ Of late, several articles have reported the efficacy of a new device called BIM (Breathe with Interactive Music, developed by InterCure, Ltd., Northern Industrial AreaLod, Israel) in reducing BPs ${ }^{1-4}$ when the achieved breathing frequency was $<10$ breaths $\mathrm{min}^{-1}$. In these studies, subjects used the device for 8 weeks, on a daily-based schedule from 10 to $15 \mathrm{~min}$. The mechanisms involved in BP reduction using breathing devices are still unclear.

Responses to different modes of breathing have been analyzed ${ }^{5,6}$ and it is believed that slow-breathing promotes a modulation of the autonomic cardiovascular regulation, characterized by increased parasympathetic activity and reduced muscle sympathetic activity. ${ }^{7}$ In the breathing cycle, the muscle sympathetic nerve activity declines during inspiration, reaching it's nadir at the end-inspiration/early-expiration, and then rises. ${ }^{8}$

There has been no investigation of the peripheral sympathetic nerve activity during slow breathing using BIM device. We hypothesize that this new technology acutely lowers the peripheral sympathetic nerve activity.

Therefore, the objective of this study was to evaluate the acute responses of the sympathetic nerve activity, BP and HR using a BIM device.

\section{METHODS}

\section{Subjects}

In all, 31 non-diabetic, non-obese mild hypertensives (systolic blood pressure (SBP): 140-159 mm Hg and/or diastolic blood pressure (DBP): 90-99 mm Hg) were included. They were all receiving stable treatment for hypertension, with no changes 1 month before the experimental session. They received 1-3 antihypertensive medications, which could be diuretics, inhibitors of angiotensin-converting enzyme, angiotensin receptor blockers or calcium channel blockers. Sympatholitics were not used. The research protocol was approved by the ethics committee of the University of São Paulo General Hospital, São Paulo, Brazil. They all signed a term of free and informed consent after the explanation and agreed to participate in the study.

\section{Study design}

The patients arrived at the laboratory for the experimental session and received additional information regarding it. At this time, they were randomly allocated to participate of either the BIM group or the control group. All patients were placed in supine position. Three BP measures were made but only the second and third measures were considered. After that the equipment for the microneurography was placed on. The nerve localization procedure could last for $45 \mathrm{~min}$. After the nerve was located, there were $5 \mathrm{~min}$ of variables recording - the baseline period. After that, patients of the slow-breathing group were instructed to perform guided-breathing for $15 \mathrm{~min}$, following the music frequency of the equipment. The control group was instructed to listen to calm music for the same period of time. This period for both groups was called the respiratory period. After that, the headphones of both groups were taken off and the recordings continued for five more minutes— the recovery period. During all periods, muscle sympathetic nerve activity, BP, heart rate (HR) and respiratory rate $(\mathrm{RR})$ were recorded by the minute.

BP and HR measurements

SBPs and DBPs and HR were recorded by a validated ${ }^{9}$ automatic oscillometric device (DX-2710; Dixtal Biomédica, Manaus, Brazil), which was placed on the left arm of the patients. 
In the beginning of the session, three measures were made, but only the second and third measurements were averaged.

During the baseline, respiratory and recovery periods, the measurements were read by the minute.

\section{Muscle sympathetic nerve activity (MSNA) recordings}

The MSNA was measured by microneurography, ${ }^{10}$ which measures sympathetic nerve activity in postganglionic type $\mathrm{C}$ fibers. For each participant, sympathetic nerve activity was recorded from a muscle fiber fascicle in the peroneal nerve, posterior to the fibular head. In brief, an active tungsten microelectrode ( $200 \mu \mathrm{m}$ in diameter) was inserted into the muscle fiber fascicle, and a reference microelectrode was inserted subcutaneously at a distance of $1-3 \mathrm{~cm}$ from the active microelectrode. The recorded signal was fed to a preamplifier (gain: 1000 ), an amplifier (variable gain: 40-60) and a bandpass filter $(700-2000 \mathrm{~Hz})$, after which it was integrated (time constant: $0.1 \mathrm{~s}$ ) to obtain a mean voltage display of the MSNA neurogram. Activity is expressed as burst frequency (bursts $\mathrm{min}^{-1}$ ). The same blinded investigator analyzed all subjects' recordings.

\section{Interventions}

The BIM device used for the breathing exercise was RESPeRATE (InteCure, Israel), which consists of a belt-type respiration sensor connected to a computerized box that generates musical patterns through earphones. The device guides the user to slow breathing by relatively prolonging exhalation and monitors breathing patterns, averaging them over the last four breaths, synthesizing musical patterns with 'inspiration' sounds, and synchronizing inhaling and exhaling with musical sounds. This device shows the patient's RR. A MP3 player playing calm music was used as an active control.

\section{Data analysis and statistics}

For data analysis, the respiratory period (RP) was divided into three phases of 5 min each: from minute 1 to minute $5-\mathrm{RP} 1$, from minute 6 to minute $10-\mathrm{RP} 2$ and from minute 11 to minute $15-\mathrm{RP} 3$. Data for both groups were compared using a two-way analysis of variance, with one between main factor (groups: BIM or control) and one within main factor (periods: baseline, RP and recovery). Post hoc comparisons were made by Newman-Keuls test. It was considered to be statistically significant $P<0.05$. Data are expressed as mean \pm s.d.

\section{RESULTS}

Three patients of the slow-breathing group were excluded because they did not reach 10 breaths $\mathrm{min}^{-1}$ using the slow-breathing device and two patients of the control group were excluded because they fell asleep during the RP. A total of 27 subjects successfully finished the protocol. In all, 14 subjects participated in the BIM group ( 8 men and 6 women) and 13 participated of the control group ( 7 men and 6 women). Table 1 shows the physical and clinical characteristics from both groups.

Figure 1 shows all variables during all periods of the study. During the baseline period all variables were similar between the BIM and control groups $(P>0.05)$ : RR values were $16 \pm 3$ beats per minute (b.p.m) and $17 \pm 4$ b.p.m, MSNA values were $44 \pm 8$ bursts $\mathrm{min}^{-1}$ and $45 \pm 9$ bursts $\mathrm{min}^{-1}, \mathrm{SBPs} / \mathrm{DBPs}$ values were $137 \pm 18 / 84 \pm 8 \mathrm{~mm} \mathrm{Hg}$ and $140 \pm 15 / 87 \pm 9 \mathrm{~mm} \mathrm{Hg}$ and $\mathrm{HR}$ values were $67 \pm 10$ b.p.m and $72 \pm 11$, respectively.

During the first RP (RP1), all patients of the BIM group reached $<10$ breaths $\mathrm{min}^{-1}$ before the fifth minute was completed; therefore, the mean of the RP1 for this group was $8.8 \pm 1.6$ breaths $\mathrm{min}^{-1}$ $(P<0.01$ compared with baseline $)$. The $\mathrm{RR}$ value for the control group at RP1 was $17.3 \pm 3.3$ breaths $\mathrm{min}^{-1}$. During RP2 and RP3, mean RR for the same group were $6.2 \pm 1.5$ and $5.5 \pm 1.8$ breaths $\mathrm{min}^{-1}$, respectively. These values were significantly lower than the baseline period value $(P<0.01$ for both $)$ and also lower than the same periods of the control group $\left(17.2 \pm 3.2\right.$ and $16.4 \pm 3.5$ breaths $\mathrm{min}^{-1}, P<0.01$
Table 1 Patient's characteristics (mean \pm s.d.)

\begin{tabular}{|c|c|c|c|}
\hline & $\begin{array}{l}\text { BIM } \\
\text { group } \\
(\mathrm{n}=15)\end{array}$ & $\begin{array}{l}\text { Control } \\
\text { group } \\
(\mathrm{n}=13)\end{array}$ & $\mathrm{P}$-value \\
\hline Age (years) & $51 \pm 9$ & $50 \pm 9$ & 0.7 \\
\hline Height (cm) & $166 \pm 11$ & $162 \pm 11$ & 0.4 \\
\hline Weight (kg) & $72 \pm 18$ & $68 \pm 14$ & 0.5 \\
\hline BMI ( $\left.\mathrm{kg} \mathrm{m}^{-2}\right)$ & $27 \pm 3$ & $26 \pm 3$ & 0.4 \\
\hline Systolic BP (mm Hg) & $137 \pm 18$ & $140 \pm 15$ & 0.7 \\
\hline Diastolic BP (mm Hg) & $84 \pm 9$ & $87 \pm 9$ & 0.3 \\
\hline Heart rate & $67 \pm 10$ & $72 \pm 11$ & 0.2 \\
\hline \multicolumn{4}{|l|}{ Antihypertensive medication } \\
\hline $\begin{array}{l}\text { One drug (ACE inhibitor or calcium channel } \\
\text { blocker or angiotensin II receptor antagonist) }\end{array}$ & 07 & 08 & 0.2 \\
\hline $\begin{array}{l}\text { Two drugs (ACE inhibitor + diuretic or } \\
\text { calcium channel blocker + angiotensin II } \\
\text { receptor antagonists or calcium channel blocker } \\
+ \text { ACE inhibitor) }\end{array}$ & 07 & 04 & 0.09 \\
\hline $\begin{array}{l}\text { Three drugs (calcium channel blocker + } \\
\text { ACE inhibitor + diuretic or angiotensin II receptor } \\
\text { antagonists + calcium channel blocker + diuretc) }\end{array}$ & 01 & 01 & 0.3 \\
\hline
\end{tabular}

Abbreviations: ACE, angiotensin-converting enzyme; BMI, body mass index; BP, blood pressure.

for both). At RP1, MSNA was similar to the baseline values for both groups: $40 \pm 7$ bursts $\mathrm{min}^{-1}$ for BIM and $43 \pm 9$ bursts $\mathrm{min}^{-1}$ for the control ( $P>0.05$ for both). During RP2 and RP3 periods, MSNA of the slow-breathing group was significantly lower than the baseline values ( $38 \pm 7$ bursts $\mathrm{min}^{-1}, 36 \pm 8$ bursts $\mathrm{min}^{-1}$, respectively $P<0.01$ for both) and also, lower than the same periods of the control group ( $44 \pm 8$ bursts $\mathrm{min}^{-1}, 43 \pm 8$ burst $\min ^{-1}, P<0.05$ for both).

The slow-breathing and control groups respectively had SBP significantly lower during RP1 (135 \pm 17 and $137 \pm 14 \mathrm{~mm} \mathrm{Hg}$, $P=0.05)$, RP2 $(132 \pm 17$ and $136 \pm 13 \mathrm{~mm} \mathrm{Hg}, P<0.01)$ and RP3 $(131 \pm 17$ and $136 \pm 14 \mathrm{~mm} \mathrm{Hg} P<0.01)$ compared with the baseline period. Compared with the baseline values, DBP was lower for slowbreathing and control groups $(P<0.01)$ during the RP2 $(82 \pm 9$ and $84 \pm 9 \mathrm{~mm} \mathrm{Hg})$ and RP3 $(81 \pm 9$ and $84 \pm 11 \mathrm{~mm} \mathrm{Hg})$, respectively. During RP2 period, HR were not different from baseline values for BIM and control groups ( $67 \pm 9$ b.p.m and $71 \pm 10$ b.p.m) $(P=0.4$ for both). At RP3 period, HR was significantly lower for both groups compared with the baseline period ( $66 \pm 9$ b.p.m and $70 \pm 11$ b.p.m for BIM and control respectively, $P<0.01)$.

During the recovery period, RR and MSNA ( $9.4 \pm 4.5$ breaths min $^{-1}$ and $36 \pm 7$ bursts $\mathrm{min}^{-1}$, respectively) for the BIM group remained significantly lower compared with the baseline period of the same group $(P<0.01$ for both). SBP $(134 \pm 18$ and $137 \pm 14 \mathrm{~mm} \mathrm{Hg})$, DBP $(82 \pm 10 \mathrm{~mm} \mathrm{Hg}$ and $85 \pm 9 \mathrm{~mm} \mathrm{Hg})$ and $\mathrm{HR}(65 \pm 11$ and $71 \pm 11)$, were significantly lower than baseline period for BIM and control respectively $(P<0.05$ for all). Figure 2 shows the nerve traffic during baseline and RP3 from one subject from each group.

\section{DISCUSSION}

This is the first study that investigated the peripheral sympathetic nerve activity during guided respiration with a BIM device. The main and new finding of this study was that during device-guided respiration peripheral sympathetic nerve activity is decreased. In this study, it was also observed that the SBPs and DBPs were reduced during slowbreathing and regular-breathing interventions. 

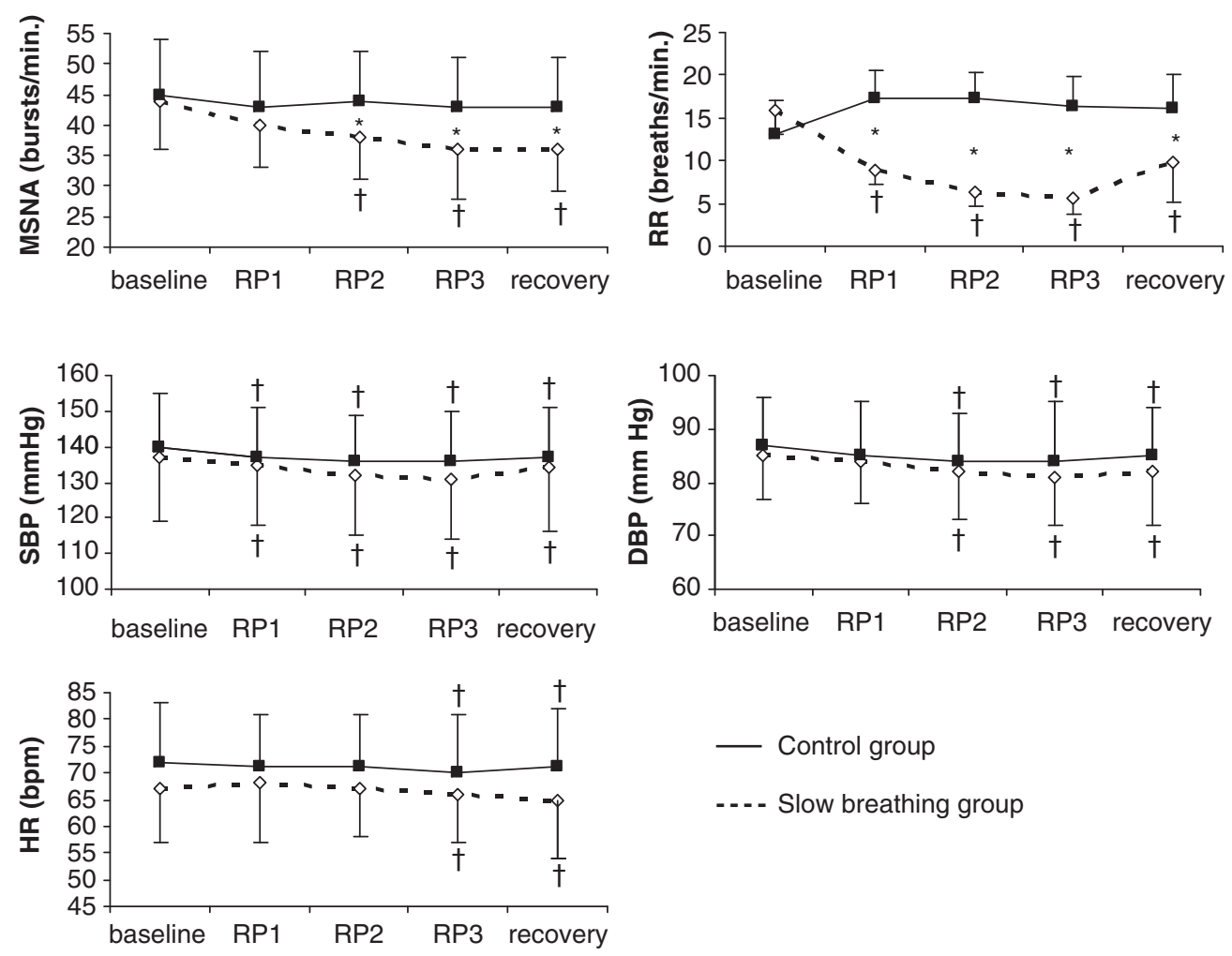

- Control group

. - . - Slow breathing group

Figure 1 MSNA, RR, SBP, DBP and HR from the slow-breathing and control groups. ${ }^{*} P<0.05$ between groups; ${ }^{\dagger} P<0.05$ compared with the baseline period.
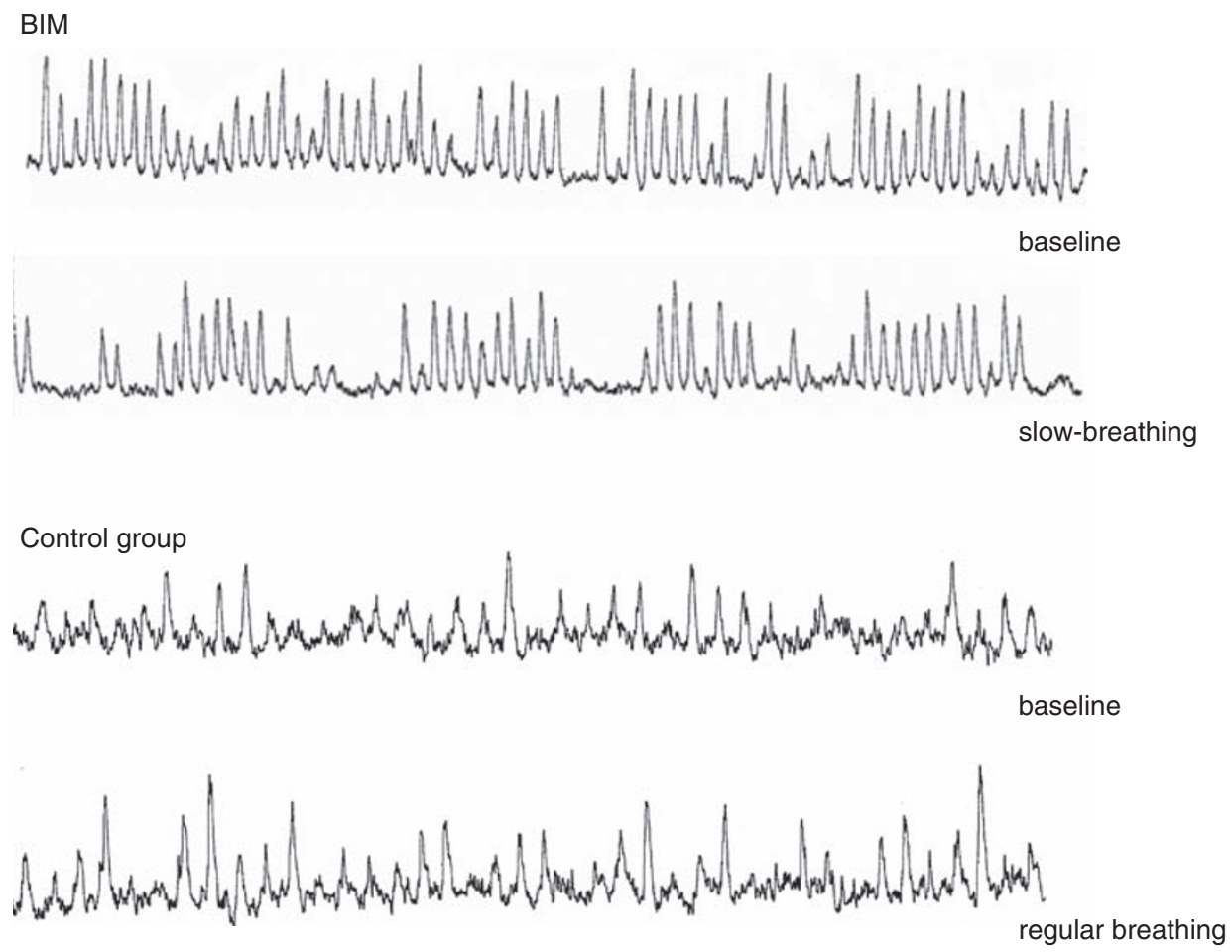

Figure 2 The sympathetic nerve traffic during the baseline and respiratory periods from the BIM and control groups.

The device used in this protocol had been used in several other studies and it's efficacy was proved after 8 weeks of continue use at patients home. ${ }^{1,4,11}$ Acutely, this is the first time that this device was used. A majority of the studies also used calm music as control.
In hypertensives, the $\mathrm{BP}$ reductions in the intervention group were more significant compared with the control group, but as observed in other studies, BP reductions were also observed when subjects were listening to music. ${ }^{1,4}$ 
In patients with type 2 diabetes, Longtenberg et al. ${ }^{11}$ showed office SBP reduction after using the BIM and listening to music and the office DBP decreased only in the group who listened to music. So, either calm music or the use of BIM reduces BP, although BIM seems to be more effective. ${ }^{4}$

We found that sympathetic nerve activity is reduced when subjects breathe slowly. The muscular sympathetic activity decreases between the fifth and tenth minutes of the BIM use. At that moment, the breathing frequency was already $<10$ breaths $\mathrm{min}^{-1}$, showing that the sympathetic activity is related to the breathing frequency. We also observed that the bursts frequency occurred most frequently during the expiration phase and it was already shown by Hagbarth and Valbo $^{12}$ so, although the BIM device prolonged the expiratory phase of respiration, the slow-breathing induced a reduction in the number of bursts compared with control. It is believed that the lung inflation exerts a modulatory influence on central sympathetic neural outflow under resting conditions. ${ }^{13,14}$

Some investigators also found that slow-breathing increases the baroreflex sensibility in hypertensives, normotensives ${ }^{15}$ and also in patients with chronic heart failure, ${ }^{16}$ what explains good results after 8 weeks of practice at home. Grossman et al. ${ }^{1}$ speculated that the repeated response to acute slow- and regular-breathing reverses the vascular pathology associated with hypertension, which is partially determined by the vascular tone, which is controlled by the sympathetic activity, and in this study, we observed that at least the peripheral sympathetic activity is reduced during slow-breathing exercises. These findings have clinical implications not only for hypertensives patients, but also in pathogenesis of human heart failure and ventricular arrhythmias ${ }^{17}$ in which the sympathetic nervous activations have an important role. It is believed that the autonomic nervous system, through stimulation of arterial baroreceptor, pulmonary stretch receptors and low pressure baroreceptors, may have important roles in changes of $\mathrm{BP}^{15,18}$ Bernardi et al. ${ }^{16}$ reported that BP decrease in slower or deeper breathing is due to relative increase in vagal activity, decreased sympathetic activity and reduced afterload.

Recently, Schein et al. ${ }^{19}$ found office SBP reduction after 8 weeks of the device use at home in type 2 diabetic patients, compared with controls. The investigators believe that the inhibition of the sympathetic outflow during exhalation and arteriolar vasodilation are responses of the pulmonary stretch receptors activated by the prolonged exhalation, although, they do not believe that this is the mechanism responsible for reducing BP in diabetic patients, because of their autonomic dysfunction. So, at least for diabetic patients there must be another mechanism responsible for BP decrease which has not been found yet. We believe that this is the same mechanism that acts reducing BP values while the subjects are listening to calm music and respiration rates are unaltered. Our findings regarding BP reductions during calm music are similar to other studies involving other interventions as meditation ${ }^{20}$ and can be explained by the subjects relaxation over time, ${ }^{1}$ as observed in other studies.

One hypothesis is that relaxation over the time evokes a parasympathetic predominance, not related to the RR, but that is enough to decrease BP. Some investigators observed this phenomenon using HR variability during meditation. ${ }^{21}$

Our decrease in BP $(-6 \mathrm{~mm} \mathrm{Hg} /-4 \mathrm{~mm} \mathrm{Hg}$ on SBP/DBP $)$ is similar to other studies that observed acute $\mathrm{BP}$ variations with slow breathing. In one study, patients breathed six times per min for only $2 \mathrm{~min}$ and had $8.6 \mathrm{~mm} \mathrm{Hg}$ reduction in SBPs and $4.9 \mathrm{~mm} \mathrm{Hg}$ in DBPs. ${ }^{15}$ In addition, $30 \mathrm{~s}$ of deep slow breathing caused $6.4 / 3 \mathrm{~mm} \mathrm{Hg}$ reductions in SBPs/DBPs in treated hypertensives. ${ }^{18}$
The percentage of BP changes seems to be related to the levels before treatment. Viskoper et al. ${ }^{22}$ observed that reductions were greater using the device for patients whose baseline BP was elevated: SBP $>140 \mathrm{~mm} \mathrm{Hg}$ and DBP $>90 \mathrm{~mm} \mathrm{Hg}$. The same investigators observed that mean arterial BP reductions occurred only in patients who had mean $\mathrm{BP} \geqslant 98 \mathrm{~mm} \mathrm{Hg}$. The subjects of most papers ${ }^{1,4,23}$ using the same device, had high BP values to start with, and also Joseph et al. ${ }^{15}$ studied untreated or patients with antihypertensive medication discontinued. We suppose that better results could be observed if baseline values from BPs were higher.

We observed no changes in the HR and this result correlates to other data involving slow/deep breathing acutely ${ }^{11}$ or chronically. ${ }^{1,3,4,23}$

It seems unlikely that the antihypertensive drugs used in the study may have influenced the MSNA. First of all, all classes of drugs were well distributed between the two groups. Second, in spite of the action of diuretics in MSNA be controversial ${ }^{24}$ increasing ${ }^{25}$ or not affecting the sympathetic nervous system, ${ }^{26}$ this class of drugs was not used as monotherapy in our patients. Finally, Schein et al. ${ }^{19}$ did not observe any influence of the hypertensive medications, including diuretics in $\mathrm{BP}$ reduction with the same device. Moreover, it is known that this device may have therapeutic potential as low-risk adjunctive therapy for hypertension. ${ }^{27}$

In conclusion, listening to calm music and the use of a BIM device decreased acutely, the BP. Reduction in peripheral sympathetic nerve activity seemed to be one of the mechanisms involved in BP changes in hypertensive patients.

\section{CONFLICT OF INTEREST}

The authors declare no conflict of interest.

1 Grossman E, Grossman A, Schein MH, Zimlichman R, Gavish B. Breathing-control lowers blood pressure. J Hum Hypertens 2001; 15: 263-269.

2 Parati G, Carretta R. Device-guided slow breathing as a non-pharmacological approach to antihypertensive treatment: efficacy, problems and perspectives. J Hypertens 2007; 25: 57-61.

3 Rosenthal T, Alter A, Peleg E, Gavish B. Device-guided breathing exercises reduce blood pressure: ambulatory and home measurements. Am J Hypertens 2001; 14: 74-76.

4 Schein MH, Gavish B, Herz M, Rosner-Kahana D, Naveh P, Knishkowy B, Zlotnikov E, Ben-Zvi N, Melmed R N. Treating hypertension with a device that slows and regularises breathing: a randomised, double-blind controlled study. J Hum Hypertens 2001; 15: 271-278.

5 St Croix CM, Satoh M, Morgan BJ, Skatrud JB, Dempsey JA. Role of respiratory motor output in within-breath modulation of muscle sympathetic nerve activity in humans. Circ Res 1999; 85: 457-469.

6 Eckberg DL, Nerhed C, Wallin BG. Respiratory modulation of muscle sympathetic and vagal cardiac outflow in man. J Physiol 1985; 365: 181-196.

7 Bernardi L, Spadacini G, Bellwon J, Hajric R, Roskamm H, Frey AW. Effect of breathing rate on oxygen saturation and exercise performance in chronic heart failure. Lancet 1998; 351: 1308-1311.

8 Seals DR, Suwarno NO, Joyner MJ, Iber C, Copeland JG, Dempsey JA. Respiratory modulation of muscle sympathetic nerve activity in intact and lung denervated humans. Circ Res 1993; 72: 440-454.

9 Mano GM, Souza VF, Pierin AM, Lima JC, Ignes EC, Ortega KC, Mion Jr D. Assessment of the DIXTAL DX-2710 automated oscillometric device for blood pressure measurement with the validation protocols of the British Hypertension Society (BHS) and the Association for the Advancement of Medical Instrumentation (AAMI). Arq Bras Cardiol 2002; 79: 606-610 . 601-605.

10 Mark AL, Wallin BG. Microneurography: a technique for assessing central neural effects of adrenergic drugs on sympathetic outflow in humans. J Cardiovasc Pharmacol 1985; 7(Suppl 8): S67-S69.

11 Logtenberg SJ, Kleefstra N, Houweling ST, Groenier KH, Bilo HJ. Effect of deviceguided breathing exercises on blood pressure in hypertensive patients with type 2 diabetes mellitus: a randomized controlled trial. J Hypertens 2007; 25: 241-246.

12 Hagbarth KE, Vallbo AB. Pulse and respiratory grouping of sympathetic impulses in human muscle-nerves. Acta Physiol Scand 1968; 74: 96-108.

13 Goso Y, Asanoi H, Ishise H, Kameyama T, Hirai T, Nozawa T, Takashima S, Umeno K, Inoue $\mathrm{H}$. Respiratory modulation of muscle sympathetic nerve activity in patients with chronic heart failure. Circulation 2001; 104: 418-423. 
14 Seals DR, Suwarno NO, Dempsey JA. Influence of lung volume on sympathetic nerve discharge in normal humans. Circ Res 1990; 67: 130-141.

15 Joseph CN, Porta C, Casucci G, Casiraghi N, Maffeis M, Rossi M, Bernardi L. Slow breathing improves arterial baroreflex sensitivity and decreases blood pressure in essential hypertension. Hypertension 2005; 46: 714-718.

16 Bernardi L, Porta C, Spicuzza L, Bellwon J, Spadacini G, Frey AW, Yeung LY, Sanderson JE, Pedretti R, Tramarin R. Slow breathing increases arterial baroreflex sensitivity in patients with chronic heart failure. Circulation 2002; 105: 143-145.

17 Esler M. The sympathetic system and hypertension. Am J Hypertens 2000; 13: 99S$105 \mathrm{~S}$

18 Mori H, Yamamoto H, Kuwashima M, Saito S, Ukai H, Hirao K, Yamauchi M, Umemura $\mathrm{S}$. How does deep breathing affect office blood pressure and pulse rate? Hypertens Res 2005; 28: 499-504.

19 Schein MH, Gavish B, Baevsky T, Kaufman M, Levine S, Nessing A, Alter A. hypertension in type II diabetic patients with device-guided breathing: a randomized controlled trial. J Hum Hypertens 2009; 23: 325-331.

20 Paul-Labrador M, Polk D, Dwyer JH, Velasquez I, Nidich S, Rainforth M, Schneider R, Merz CN. Effects of a randomized controlled trial of transcendental meditation on components of the metabolic syndrome in subjects with coronary heart disease. Arch Intern Med 2006; 166: 1218-1224.
21 Wu SD, Lo PC. Inward-attention meditation increases parasympathetic activity: a study based on heart rate variability. Biomed Res 2008; 29: 245-250.

22 Viskoper R, Shapira I, Priluck R, Mindlin R, Chornia L, Laszt A, Dicker D, Gavish B, Alter A. Nonpharmacologic treatment of resistant hypertensives by device-guided slow breathing exercises. Am J Hypertens 2003; 16: 484-487.

23 Meles E, Giannattasio C, Failla M, Gentile G, Capra A, Mancia G. Nonpharmacologic treatment of hypertension by respiratory exercise in the home setting. Am J Hypertens 2004; 17: 370-374.

24 Hjemdahl P. Sympatho-adrenal mechanisms and the antihypertensive response to thiazide diuretics. Acta Pharmacol Toxicol (Copenh) 1984; 54(Suppl 1): 43-46.

25 Menon DV, Arbique D, Wang Z, Adams-Huet B, Auchus RJ, Vongpatanasin W. Differential effects of chlorthalidone versus spironolactone on muscle sympathetic nerve activity in hypertensive patients. J Clin Endocrinol Metab 2009; 94: 13611366

26 Grassi G, Seravalle G, Dell'Oro R, Trevano F Q, Bombelli M, Scopelliti F, Facchini A, Mancia G. Comparative effects of candesartan and hydrochlorothiazide on blood pressure, insulin sensitivity, and sympathetic drive in obese hypertensive individuals: results of the CROSS study. J Hypertens 2003; 21: 1761-1769.

27 Jagomagi K, Raamat R, Talts J, Lansimies E, Jurvelin J. Effect of deep breathing test on finger blood pressure. Blood Press Monit 2003; 8: 211-214. 